\title{
A Smart Governance diffusion model for blockchain as an anti-corruption tool in Smart Cities
}

\author{
Claris Parenti ${ }^{a}$, Negar Noori ${ }^{\mathrm{b}}$ and Marijn Janssen ${ }^{\mathrm{c}, *}$ \\ ${ }^{a}$ Rotterdam School of Management, Erasmus University, The Netherlands \\ E-mail: claris.parenti@gmail.com \\ ${ }^{\mathrm{b}}$ Erasmus School of Law, Erasmus University, The Netherlands \\ E-mail:noori@law.eur.nl \\ ${ }^{\mathrm{c}}$ Faculty of Technology, Policy \& Management, Delft University of Technology, The Netherlands \\ E-mail: m.f.w.h.a.janssen@tudelft.nl
}

Received 29 November 2021

Accepted 11 January 2022

\begin{abstract}
Government corruption in Latin America prevents the region's sustainable development and constitutes a failure of current systems. Governments have started to leverage new technologies to increase transparency and promote integrity within their processes. Among these, blockchain technology has gained traction as a promising tool for Smart Governance due to its unique properties in terms of immutability, trust, coordination, security, and transparency. The use of blockchain within Smart City initiatives is complicated by a lack of diffusion models. This paper develops a diffusion model for blockchain technology after analyzing three case studies and conducting a survey of thirty blockchain start-up leads across Latin America. The final model, named Smart Governance BT diffusion model, conceptualizes the diffusion of blockchain as a gradual process including inputs, a dynamic throughput, and outputs. Relevant for academics and government representatives alike, the model aims at improving the conceptual understanding of technology diffusion in Smart Cities and highlights the potential of blockchain as a mitigator of vulnerabilities to corruption. As initial conditions matter for its successful adoption and diffusion, it is recommended for Latin American governments to (1) redesign and digitalize their processes and legislation, (2) conduct a thorough cost-benefit analysis for specific use cases, and (3) reduce inefficiencies in areas with relatively medium to low levels of historical corruption in a first instance. The model can be tested and refined in future research and can be applied to any Smart City initiative requiring conceptualization.
\end{abstract}

Keywords: Blockchain, Corruption, Smart Cities, Latin America, Digital government

\section{Introduction}

Government corruption is a deep-rooted and systemic problem around the world, constituting a barrier to social, economic, and environmental development [11]. Nevertheless, the increasing digitalization of the public sector gradually provides opportunities for reducing corruption. The most common causes of government corruption include

*Corresponding author. E-mail: m.f.w.h.a.janssen@tudelft.nl. 
low levels of transparency, poor record-keeping, and a lack of public accountability [11]. Blockchain technology (BT) has increasingly triggered academics and governmental bodies' attention as a new and disruptive technology able to "secure transactions and tamper-proof records, making them corruption-resilient with an unalterable audit trail" [34]. The use of BT in the public sector inscribes itself in the larger domain of the transition to models of Smart Governance and digital governments within Smart Cities - urban environments predominantly composed of ICTs allowing to develop, deploy, and promote an efficient relationship between data and its applications for sustainable development [15]. Current research on Smart Governance highlights that the use of blockchain increases efficiency, transparency, and citizen trust within the public administration of Smart Cities while providing greater privacy to citizens through more "personalized, convenient, and inclusive access to high-quality public services" [38].

A blockchain can be defined as a "digital, decentralized, and distributed ledger in which transactions are logged and added in chronological order to create permanent and tamper-proof records" [38]. The three main functions of blockchain can be summarized as (1) storing information, (2) tracking the exchange of value, and (3) digitizing and automating rules through Smart Contracts [40]. Addressing vulnerabilities to corruption - such as bureaucratical inefficiencies and lack of record integrity - is critical to ensure the sustainability of developmental initiatives through the prevention of capital outflow slowing down progress. In this sense, several blockchain characteristics become relevant. Blockchain's decentralized model allows for the disintermediation of transactions, enabling trust between unknown parties [39]. Limiting physical interaction with assets using blockchain technology is highly relevant in environments where "trust in data is greater than in individuals or institutions" [1]. Distributed registers provide greater service availability and resilience of digital services, while security is established through encryption keys, information redundancy, and Byzantine fault-tolerance [18]. Constant records provide high levels of auditability, blockchain acting as a reliable digital accounting system where records are time-stamped and append-only. Consequently, the latter is estimated to provide law enforcement with the necessary digital clues to identify illicit activities [32]. All being considered, BT is expected to bring three crucial value propositions for corruption management, namely (1) verifying identity, (2) registering assets, and (3) tracking transactions [32].

Although blockchain's disruptive features and newness have generated enthusiasm in terms of the applications in the public sector, several academics warn against unrealistic expectations and call for a careful analysis of whether the technology is applicable and relevant to a certain institutional context before adopting it. Previous research on Smart City readiness estimates that "technology-enabled smart cities can only be realized when concurrent socio-economic, human, legal, and regulatory reforms are embedded in long-term developmental trajectories" [37]. Countries leapfrogging institutional development stages by adopting blockchain-based Smart Governance reforms straight away may fail in doing so. An example is the recent move from El Salvador, which became the first country worldwide to adopt Bitcoin - cryptocurrencies being an application of blockchain technology - as legal tender in June 2021 [30]. Initially met by enthusiasm, shortcomings can already be seen as the International Monetary Fund (IMF) mentions "macroeconomic, financial, and legal issues", while the World Bank refuses to provide implementation assistance given environmental and transparency shortcomings [6].

This paper investigates how Smart Governance initiatives using BT can be conceptualized as a developmental process by developing a model of diffusion for successful solutions. Diffusion models are currently lacking from academic research and constitute a missed opportunity to assist the decision-making of national and local governments. Indeed, much is being speculated about blockchain's potential as an anti-corruption tool, while few know how to develop solutions in practice. Moreover, current Smart Governance initiatives using blockchain have mostly been researched in developed countries, calling for a "deeper understanding of facilitative policy conditions unique to developing countries" [42]. Therefore, Latin America (LATAM) is the geographical focus of this research, as a region continuously disturbed by large government corruption scandals reflecting the weakness of its central governments and their distortions. Brazil's scandal of the Lava-Jato, where the nation's largest construction firms were found to bribe public sector officers in Brazil, Bolivia, Ecuador, Mexico, Peru, and several other countries, shows how corruption scandals have no borders, justifying studying the region in its entirety [31]. Public procurement is at the center of most scandals, making it the primary source of bribery occurrences in the region [31]. Although punitive measures exist for corrupt public agents, sanctions are not consistently imposed, as the judiciary system itself is susceptible to bribery or political influence [18]. As such, it has been estimated that the probability of being convicted for corruption offenses in Brazil is less than 5\% [18]. 
Hence, proactively limiting opportunities for corruption is imperative to efficiently minimize its socio-economic and political consequences. The emergence of Smart Governance models provides an opportunity to investigate alternative administrative structures able to improve efficiency and public accountability, including blockchain initiatives [39]. Latin America has already reportedly been implementing blockchain-based systems at national and local governmental levels. For example, Brazil's federal government has started BT initiatives for finance, tax, and pension purposes, while a system of cross-border payments and customs recognition among LATAM countries is currently being developed.

Nevertheless, documentation on initiatives is limited while projects are recent and not fully tested, calling for further inquiry. Considering the uncertainties revolving around blockchain's value proposition, the readiness of adoption in the Latin American context, and the lack of guidelines to implement it, the following research questions are formulated to guide the development of the diffusion model:

a) What is blockchain's value proposition in reducing vulnerabilities to government corruption in the Latin American context?

b) To what extent is Latin America ready to adopt blockchain within its public sector?

c) What are the expected contingencies related to the diffusion of blockchain technology within the Latin American public sector?

The paper is structured as follows. First, the research approach containing the data collection and methodology is outlined. Next, an integrative literature review is performed to gather diffusion contingencies from previous research in the field. Then, the outcomes of three case studies in Colombia, Mexico, and Chile are presented to answer the first sub-research question, which aims to showcase the value proposition of the diffusion model. Indeed, analyzing case studies is primordial to understand the diffusion, design, and governance of such projects while determining their efficiency in reducing pre-existing vulnerabilities to corruption. Answering the second and third sub-research questions and given the significant amount of positivity bias around the technology's potential, the literature review outcomes and expert opinions from 30 blockchain start-up leads in LATAM gathered through a survey are integrated into a final diffusion model. Named Smart Governance BT diffusion model, the model aims to provide researchers and policy-makers with the intricacies of blockchain adoption in the Latin American public sector. The paper is finally concluded by a discussion of results and suggestions for future research.

\section{Data collection and methodology}

Given the limitations of existing blockchain uses and the variety of applications, there is a need to analyze what motivates specific departments of the public administration to use the technology. Answering the first subresearch question, this paper starts by examining existing blockchain initiatives in the Latin American public sector to understand their feasibility and practical contributions through a small-N case comparison. Small-N case comparisons allow for "systematic comparative illustrations for insight-generating and in-depth studies of cases as a whole" [23]. This first part of the research process does not intend to feed the diffusion model directly, but rather to tackle the current underrepresentation in academia of existing Latin American initiatives in the field, as well as to provide an overall understanding of the value proposition of blockchain applied to specific examples in the public sector. An overview of the respective case studies is available in Table 1. Following previous research on blockchain adoption [16,29,38], Rogers' (1962) Diffusion of Innovation (DOI) theory is used to understand the factors that led to the adoption of BT in the case studies, namely relative advantage, compatibility, complexity, trialability, and observability. Case studies were deductively coded and selected based on the following criteria: (1) the project employed blockchain technology, (2) the project is completed, and results are readily observable, (3) the project aims at increasing transparency within processes, (4) information is readily accessible and when not available complemented during the interview, and (5) the project was implemented within the public sector of a Latin American country. Two semi-structured interviews were conducted online through a predetermined question guide. Transcripts were then translated from Spanish to English and deductively coded. 
Table 1

Overview of case studies

\begin{tabular}{|c|c|c|c|c|c|}
\hline Country & Project name & Field & Level of government & Year & Interview \\
\hline México & $\begin{array}{l}\text { Sistema de Gestión de } \\
\text { Correspondencia y Archivo }\end{array}$ & $\begin{array}{l}\text { Digital certification of } \\
\text { legislative documentation }\end{array}$ & $\begin{array}{l}\text { Congress of Quintana Roo } \\
\text { (Congreso del Estado de } \\
\text { Quintana Roo) }\end{array}$ & 2020 & $\begin{array}{l}\text { Yes, Ricardo Vázquez } \\
\text { Gutiérrez, Business } \\
\text { Development of Ava Labs } \\
\text { in Latin America. }\end{array}$ \\
\hline Chile & Energía Abierta & $\begin{array}{l}\text { Digital certification of } \\
\text { transaction and information } \\
\text { data }\end{array}$ & $\begin{array}{l}\text { National Energy } \\
\text { Commission (Comisión } \\
\text { Nacional de Energía } \\
(\mathrm{CNE}))\end{array}$ & 2018 & $\begin{array}{l}\text { Yes, Marcos Ariel } \\
\text { Malamud, executive } \\
\text { director at Mismática } \\
\text { Management. }\end{array}$ \\
\hline Colombia & $\begin{array}{l}\text { The Transparency Project: } \\
\text { Unlocking Government } \\
\text { Transparency with } \\
\text { Blockchain technology }\end{array}$ & $\begin{array}{l}\text { E-procurement platform for } \\
\text { the national public-school } \\
\text { meal program }\end{array}$ & $\begin{array}{l}\text { Ministry of National } \\
\text { Education (Ministerio de } \\
\text { Educación Nacional) }\end{array}$ & 2020 & $\begin{array}{l}\text { No, enough information } \\
\text { available in reports from the } \\
\text { World Economic Forum } \\
\text { (WEF). }\end{array}$ \\
\hline
\end{tabular}

The assumption behind developing the diffusion model is that "for any transformative technological innovation to realize its socio-economic benefits, it needs to be widely adopted and diffused" in a given context [35]. Blockchain will - logically-so - not solve government corruption on its own and requires other contextual considerations for a transition to less corrupt governments. Following these assumptions, an outline of the elements to be included in the diffusion model is created by critically evaluating the Theory of Change (ToC) [3] and the Input-Output (IO) model [25]. A ToC describes "how and why an intervention is assumed to lead to a desired end-result" [22]. It is a widespread tool in both academic and public sector research to define complex issues and connect activities to outcomes [3]. Assumptions about behavior, causal relations, and contexts are explicit and supported by evidence [22]. The input-output (IO) modeling approach translates different components of a process into inputs and outputs and pinpoints them in a development process to reveal their interaction. Developed by Noori et al. (2020), the model was conceptualized for "a city in an institutional environment in which a local government wishes to develop itself into a Smart City" [25]. Integrating the ToC and the IO model components, the resulting outline of the diffusion model attempts to exhaustively gather all contingencies related to the diffusion of a Smart Governance initiative (Fig. 1).

Answering the second and third sub-research questions, identifying and prioritizing the key contingencies related to the diffusion of blockchain technology within the Latin American public sector into a conceptual model is done via an integrative literature review followed by a structured questionnaire.

First, the integrative literature review consists of tentatively exhaustively listing all contingencies related to each element of the diffusion model outline found by previous research on the field. As one of the first papers on this topic, the existing body of research reviewed is not specifically bound to the Latin American public sector and/or blockchain technology, which justified the use of a structured questionnaire to gather expert opinions on their relevance in the final diffusion model.

Based on the integrative literature review, the Inputs section of the model is filled. This paper approaches Inputs as a proxy for readiness. The current body of research on blockchain readiness is nascent and mainly revolves around the creation of Blockchain Readiness Composite Indexes (BRCI). Creating BRCIs for the public sector proves relevant for two reasons: (1) governmental authorities often fail to capture the set of variables that measure a country's capacity to adopt blockchain and (2) there is a lack of benchmarking tools identifying which countries are becoming blockchain 'friendly' for companies to host their operations and make investment decisions [14]. Quantitative indicators were chosen based on previous academic research $[4,14,43]$ and the criteria from the widely cited "Handbook on Constructing Composite Indicators" from the OECD, namely analytical soundness, country coverage, relevance, interrelatedness, and measurability [26]. For qualitative indicators of readiness, Boolean measures based on desk research are used. Assuming a complete dataset for the three pillars of socio-economic, technological, and political readiness as determined in the integrative literature review (Section 3), indicators are normalized under Excel using the standardization function (Z-score) to make them comparable. Then, the mean of the normalized scores per pillar and per country is computed. Finally, the mean of the three pillars is calculated to return the final aggregated country score. The final score is meant to quantify and rank the overall blockchain readiness of the corresponding country 


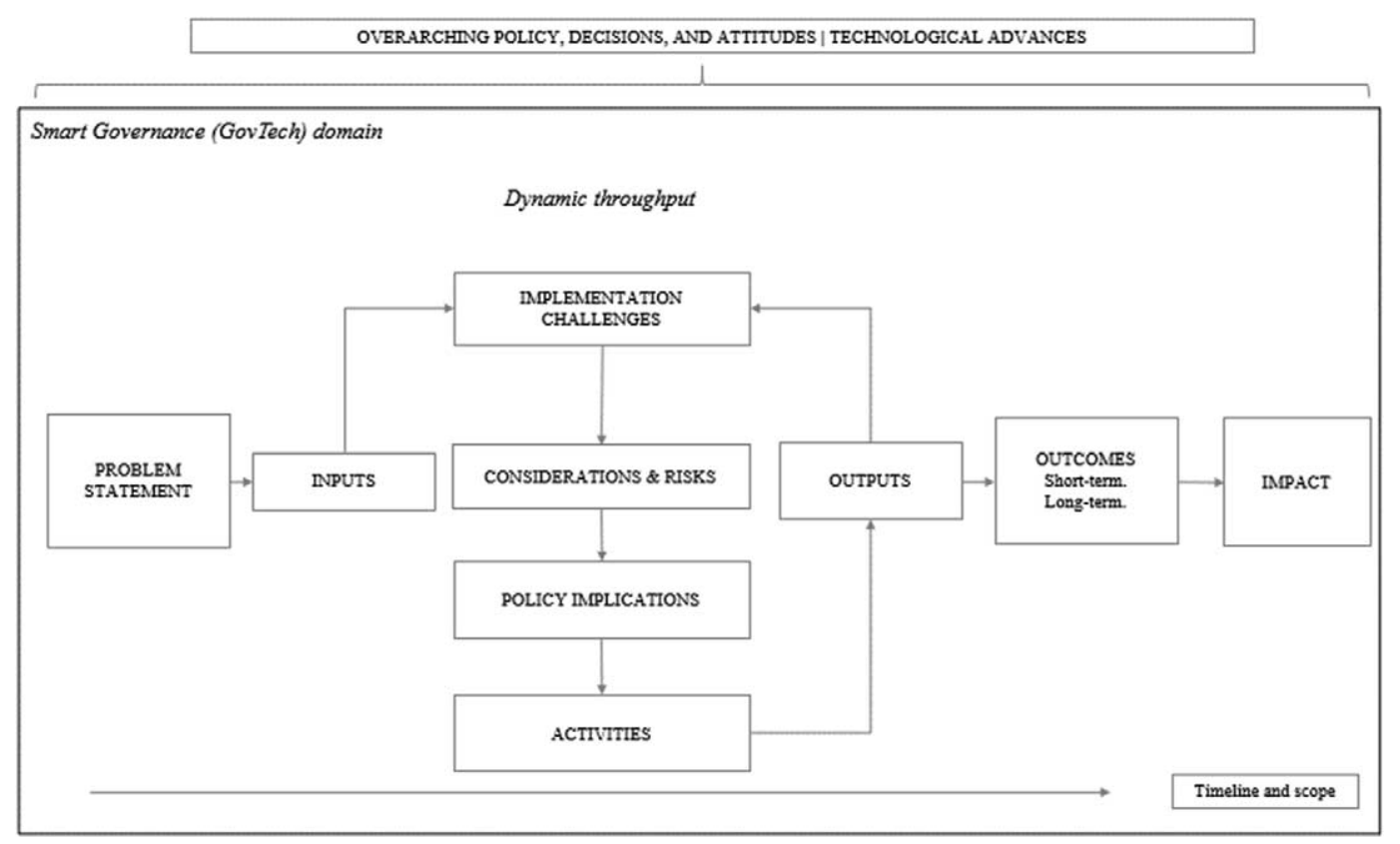

Fig. 1. Smart Governance diffusion model.

in terms of technological, socio-economic, and political readiness. Weights were not assigned across pillars as they are treated with equal importance.

Due to missing data on most countries of the Latin American region, 14 countries are selected for the readiness assessment following the GovTech 2020 Index [43], namely Argentina, Bolivia, Brazil, Chile, Colombia, Costa Rica, Dominican Republic, Ecuador, Mexico, Panama, Paraguay, Peru, Uruguay, and Venezuela. Selecting a limited number of countries to be included is deemed necessary given data availability and feasibility constraints, although consisting of a limitation to the generalizability of results. Due to data limitations and lack of leverage in terms of access, the indicators were retrieved from the year 2016 to 2020.

The Outputs, Outcomes, Impact, and Timeline \& scope sections of the model are filled with the results of a structured questionnaire of 30 blockchain leads in Latin America, where respondents were asked to rank the salience of each contingency outlined in the literature review, as well as providing their opinion on the suitability of blockchain and their views on the feasibility of diffusion within their country's public sector. The structured questionnaire is based on the methodology from authors on similar topics [21,42] by including both 7-point Likert scales for questions requiring assessments and open-ended questions to gather expert insights. The Likert-scales are used to rank the different elements of the diffusion model present in the Dynamic throughput by contrasting the means and standard deviations of responses, while open-ended questions are inductively coded.

The survey was sent to GovTech and blockchain start-up leads throughout Latin America. Choosing start-ups as a population is relevant as start-ups in blockchain and GovTech initiatives are usually directly engaged in multilateral developments and have in-depth technical knowledge [21]. The Crunchbase start-up database was used to retrieve the desired database of survey recipients. Start-ups were filtered based on their location in LATAM and domain, namely Blockchain, CivicTech, Government, GovTech, Law Enforcement, and Politics. This process yielded a total of 246 start-ups located in 14 countries. An amount of 30 respondents was achieved and considered representative given time, financial, and individual leverage constraints, corresponding to a $12.2 \%$ response rate (Appendix A). It is not uncommon that blockchain taxonomies focus on start-ups, as the topic is highly novel [21]. The survey adopts an expert perception survey approach by targeting individuals who are both knowledgeable on their country, governance, and BT. This approach is justified and has already been used [42] as blockchain is a relatively new concept to most Latin American societies, and the most useful insights can be gained from a focused sample. An 
average score above 4.0 implies a positive overall perception for each Likert scale, and an average score below 4.0 implies a negative overall perception.

In terms of language considerations, both interviewees and survey recipients were individually contacted through LinkedIn via direct messaging. Expert opinions were transcribed and translated from Spanish and Portuguese truthfully by the ability of the author to preserve intrinsic meaning. A recapitulative overview of the research process is visually represented in Appendix B.

\section{Literature review}

Current bodies of research mainly stress that whether the adoption of blockchain is transformative mostly relies on contextual elements rather than on the technology itself, especially in terms of pre-existing legal and digital infrastructure and social and political settings [1]. The integrative literature review narrates the basis for answering the second and third sub-research questions by orderly following the diffusion model elements (Fig. 1).

Considering a certain problem statement that a Smart Governance initiative aims to address, several inputs (or resources) are necessary as determinants of readiness to enter the dynamic throughput. Early blockchain experiments within the public sector have shown that the initial conditions matter and are critical to the successful diffusion of blockchain-based solutions. A total of 14 inefficiencies was derived from the research process [18], providing further background to government corruption in the Latin American context (Table 2).

Inputs include the socio-economic, technological, and political prerequisites associated with the readiness of adoption of Latin American countries to implement and scale blockchain-based solutions within their public sectors. These three pillars were selected based on the previous research on Smart City readiness from Noori, Jong \& Hoppe [24]. Although not directly focused on blockchain readiness, the authors' framework illustrates that the implementation of blockchain within the public sector is not only determined by technological capacities, but as part of a Smart Governance initiative involving multiple stakeholders such as governments, the private and public sectors, and society to a larger extent. Technological readiness is defined as the readiness of ICT-based infrastructures. Socio-economic readiness revolves around the readiness of the human and entrepreneurial infrastructure, in terms of education, propensity for innovation, and supportive systems for start-ups and innovative companies. Finally, political readiness refers to the relationship between policy institutions and political activities, next to transition management processes, including the formulation of visions and strategies. Hence, it refers to the government's capacity to handle complexity through its governance model, policy instruments, and non-institutional mechanisms including public-private partnerships (PPP), subsidiaries, negotiations, and citizen participation. After a critical evaluation of Smart City, blockchain, and GovTech readiness models from previous authors [4,5,25,43], a set of indicators is compiled and listed under the Inputs category (Table 3). All models reviewed highlight the need for proactive collaboration among stakeholders from the ecosystem, governments, policy-makers, and regulators.

Once prerequisites are fulfilled and a government decides to use blockchain in a certain field, the initiative enters a Dynamic throughput where it needs to consecutively and iteratively deal with diffusion Challenges linked to a certain technology, Considerations \& risks, and Policy implications leading to the Activities being a progressive technology diffusion.

Countries that have the most to gain from blockchain-based solutions will also face the most Challenges [32]. The most important diffusion challenges pertain to privacy and security concerns, security issues - such as endpoint vulnerabilities and untested code at a large scale - can inversely impact blockchain's diffusion within governments [28]. As blockchain records are publicly viewable and immutable, personal information may be permanently disclosed by non-authorized parties without approval from data owners [2]. Lack of perceived usefulness of BT due to the lack of skilled professionals able to use and understand the technology within the public sector is another significant challenge. As a complex technology, a lack of mass understanding and knowledge about blockchain among key stakeholders leads to skepticism or positivistic biases, both slowing down diffusion [33]. Challenges regarding legal and ethical issues, establishing standards, and regulatory compliance may also impact the viability of BT use in the public sector [28]. In addition, installing, maintaining, and securing blockchain systems imply a high initial cost of implementation [33]. Besides, records in the blockchain are limited in size, node availability, and frequency. For this reason, governments must ensure whether the benefits of implementing blockchain outweigh the costs, especially 
Table 2

Vulnerabilities to corruption in Latin America

Vulnerability to corruption
Lack of accountability and audit
Lack of transparency
Excessive bureaucracy
Corrupt behavior of public and political
agents

Lack of compliance in the public sector

Information asymmetry leading to gullible citizen-government relationships

Non-effective governance in the public sector

Public agents' discretionary power misuse

Generalized corruption perception

Impunity

Social normative pressures to engage in corruption

High tolerance to illegal behavior

Inequalities leading to elite capture of political processes

Lack of citizen participation in political processes

Description

Superficiality and an insufficient number of audits imply precariousness of supervision and difficulty of assessing public information. Intricate to identify who is responsible for what, before whom, and when.

Democracy is built on transparency and truthful citizen-government relations. Low transparency comprises its effectiveness. Information needs to be accessible and timely, as well as comprehensible for all citizens.

Excessive bureaucracy and regulations imply slow processes creating a vulnerability to corruption as the latter may be instigated to speed up the process.

Civil servants create vulnerabilities by selling unethical services, focusing on their gain. Corrupt behaviors can be perpetuated and socialized to persuade newcomers to accept corruption acts as normal in some contexts.

Audit influences public transparency and contributes to the fight against corruption and compliance with laws and regulations. Fragile audits and ambitious norms that are difficult to comply with or come with high costs lead to this vulnerability.

The fewer citizens have access to information, the more they tend to exhibit gullible behavior resulting from an inadequate educational background that can facilitate corrupted actions.

The fight against government corruption depends on good management practices. Lack of effective planning is associated with higher last-minute investments and the necessity of claim urgency, consequently leading to buying or contracting without bidding.

The greater the bureaucratic apparatus, the greater will be the discretionary space in which a public servant can serve its interests.

Disbelief and mistrust in public institutions weaken democracy. The perception that corruption is widespread and deeply entrenched threatens economic and social development, acting as a vicious cycle.

Judiciary systems are susceptible to bribery or political influence and may not impose sanctions consistently. Certain judiciary systems do not adopt corporate criminal responsibility for crimes related to corruption, where it falls only under civil and administrative law.

Widespread corruption generates the idea that the ones who do not take advantage are not smart.

The acceptance of public agents who are corrupt but have a satisfactory administration is maximized by the low educational background of citizens - i.e. in certain cases, corruption is accepted if the politician still helps the population.

Corruption is both a cause and consequence of inequality. Corruption may increase inequality by affecting income distribution and decision-making in public expenditure. Inequality might also help to promote corrupt behavior by elite capture of political processes or through the vulnerability of poorer classes to engage in clientelist relationships or to be asked for bribes [44].

Low citizen participation makes it easier to commit and hide corruption when the population does not have to be aware of it. Society's effective participation in public management brings citizens closer and improves democracy.

when considering the need for digitalized records and the technology's high energy consumption [28]. Resistance and reluctance to adopt and use BT exacerbates the implementation challenges within the public sector. Countries characterized by large corruption scandals often observe resistance from corrupt officials who benefit from current systems and fear losing perks and/or their positions [33].

Next to the diffusion challenges, several Considerations \& risks were salient in the literature and need to be considered when rolling out blockchain initiatives. Blockchain's potential is likely to have a greater impact when combined with other technologies from Industry 4.0 [14]. Environmental damage and vulnerable communities need to be considered as they could affect the modalities of diffusion. Latin American urban areas are often characterized by a central region with a municipality, a commercial area, wealthy neighborhoods, and surrounding pockets of poverty. Smart City initiatives may contribute to pushing problems into marginalized regions and creating unseen 
Table 3

Overview of components for the theoretical model of Smart Governance BT diffusion

\begin{tabular}{|c|c|c|}
\hline & Facet & Indicators and sources \\
\hline \multirow[t]{23}{*}{$\begin{array}{l}\text { Inputs } \\
(\mathrm{BRCI})\end{array}$} & \multirow[t]{10}{*}{$\begin{array}{l}\text { Political } \\
\text { readiness }\end{array}$} & $\begin{array}{l}\text { Importance of ICTs to government vision of the future (WEF Networked Readiness Composite Indicator, } \\
\text { 2016) }\end{array}$ \\
\hline & & National GovTech strategy [43] \\
\hline & & Regulations on blockchain [7] \\
\hline & & Government effectiveness (World Bank World Governance Indicators, 2019) \\
\hline & & Spending on R\&D (Global Competitiveness Report, 2018) \\
\hline & & Data protection and privacy laws (UN Data Protection and Privacy Laws Worldwide) \\
\hline & & Political stability (World Bank World Governance Indicators, 2019) \\
\hline & & Blockchain projects within governments (Blockchain in Government Tracker \& LACChain, 2018) \\
\hline & & Regulatory quality (World Bank World Governance Indicators, 2019) \\
\hline & & Rule of law (World Bank World Governance Indicators, 2019) \\
\hline & \multirow{8}{*}{$\begin{array}{l}\text { Socio-economic } \\
\text { readiness }\end{array}$} & Capacity for innovation (WEF Networked Readiness Composite Indicator, 2016) \\
\hline & & University-industry collaboration in R\&D (WEF Global Competitiveness Composite Indicator, 2018) \\
\hline & & Ease of starting a business (World Bank Ease of Doing Business Score, 2020) \\
\hline & & Digital skills in population (WEF Global Competitiveness Composite Indicator, 2018) \\
\hline & & Number of GovTech SMEs (Crunchbase, Angel, LASD, Startupxplore, 2021) \\
\hline & & Number of blockchain and GovTech start-ups (Crunchbase, 2021) \\
\hline & & Venture capital availability (WEF Networked Readiness Composite Indicator, 2016) \\
\hline & & Voice and accountability (World Bank World Governance Indicators, 2019) \\
\hline & \multirow{5}{*}{$\begin{array}{l}\text { Technological } \\
\text { readiness }\end{array}$} & E-government development (UN e-Government Composite Indicator, 2020) \\
\hline & & $\begin{array}{l}\text { Government procurement of advanced technology products (WEF Global Competitiveness Composite } \\
\text { Indicator, 2018) }\end{array}$ \\
\hline & & Cybersecurity (Global Cybersecurity Composite Indicator, 2018) \\
\hline & & ICT development level (ITU IDI Composite Indicator, 2017) \\
\hline & & Open data (Global Open Data Composite Indicator, 2016) \\
\hline \multirow[t]{22}{*}{ Throughputs } & \multirow{15}{*}{$\begin{array}{l}\text { Implementation } \\
\text { challenges }\end{array}$} & Security concerns $[28]$ \\
\hline & & Integration with government legacy systems [28] \\
\hline & & Scalability of solutions [28] \\
\hline & & Lack of adequate skills [28] \\
\hline & & Lack of understanding and knowledge [28] \\
\hline & & Regulatory compliance [28] \\
\hline & & Privacy issues [2] \\
\hline & & Resistance of corrupt agents to adopt blockchain in the public sector [16] \\
\hline & & Reluctance from the government to use blockchain technology [27] \\
\hline & & Lack of standards [28] \\
\hline & & Legal \& ethical issues [28] \\
\hline & & Lack of validation from testing [28] \\
\hline & & Initial cost of diffusion [28] \\
\hline & & Latency cost due to need for synchronization [32] \\
\hline & & Lack of flexibility from immutability [28] \\
\hline & \multirow{7}{*}{$\begin{array}{l}\text { Considerations } \\
\& \text { risks }\end{array}$} & Blockchain needs to be combined with other technologies to have potential as an anti-corruption tool [14] \\
\hline & & Need for trusted gatekeepers [1] \\
\hline & & Excessive speculation around blockchain's potential [20] \\
\hline & & Maturity of blockchain technology [20] \\
\hline & & Rebound effect by prioritizing cities over vulnerable communities [27] \\
\hline & & Blockchain may be used for corruption practices $[2,35]$ \\
\hline & & Environmental damage of blockchain $[1,9,10]$ \\
\hline
\end{tabular}


Table 3

(Continued)

\begin{tabular}{lll}
\hline & Facet & Indicators and sources \\
\hline Throughputs & Policy & Creating a supportive ecosystem that nurtures start-ups and promotes PPP [37] \\
(Continued) & implications & Developing human capital land promoting digital inclusivity [37] \\
& & Constructing regulatory models for Smart Governance [37] \\
& Encouraging citizen participation [37] \\
& Stepping up effort to fulfill basic infrastructure needs [37] \\
& Raising revenues and diversifying financing sources [37] \\
& Promoting environmental sustainability [37] \\
& Registering assets [30] \\
& Tracking transactions [30] \\
& Blockchain & Verifying identity [30] \\
& E-voting [14] \\
&
\end{tabular}

challenges for the most vulnerable communities [27]. Blockchain applications such as cryptocurrencies may be used to hide corrupt activities [2]. Moreover, although secure, blockchains are hypothetically not shielded from $51 \%$ attacks, where an actor controlling $51 \%$ or more of the mining power on the network may create new branches able to overwrite and reverse transactions on a public blockchain [35]. BT cannot ensure the validity of data if the data itself is flawed, highlighting a need for trusted gatekeepers to "ensure that the physical reality and digital information correspond" [1]. As a newly emerging and evolving technology, blockchain developments still need to gain in maturity. Significant amounts of speculation and misconception about BT may lead to biased speculations of its potential. Blockchain will need to evolve before it can fully be integrated into society, given the technological, socio-economic, and political barriers to overcome prior [20].

The previously-outlined contingencies for BT adoption and diffusion translate into tangible Policy implications for Smart Governance in developing countries, namely: (1) creating a supportive ecosystem that nurtures start-ups and promotes PPP, (2) developing human capital land promoting digital inclusivity, (3) constructing regulatory models for Smart Governance, (4) encouraging citizen participation, (5) stepping up effort to fulfill basic infrastructure needs, (6) raising revenues and diversifying financing sources, and (7) promoting environmental sustainability [37].

Once the Dynamic throughput is apprehended, the Outputs (or applications) of the technology can be seen. A feedback loop links back to the Dynamic throughput in the occurrence of unexpected or unforeseen Challenges. The Outputs then lead to the short-term and long-term Outcomes, which finally create the Impact that was aimed by the attempted solvation of the Problem statement.

Outputs include the main applications of blockchain technology ranked by salience. Blockchain can be used to create tamper-proof registries for any sort of assets, such as land title registries and documents [32]. Land registries are particularly important in corruption-prone areas to prevent unjust seizures of land. Blockchain can be used to track high-risk transactions, including public procurement transactions, pension funds, and cash transfers. Hence, blockchain allows locking in critical information at every step of transaction chains [32]. Blockchain has a value proposition for the verification of identity and protection against identity theft. The absence of efficient identity verification contributes to fraud and generates barriers to financial inclusion [32]. Another significant application is blockchain-based voting platforms that could "minimize election tampering and enhance voter trust in democratic outcomes" [14].

The intended Outcomes of implementing BT in the public sector lie in the reduction of vulnerabilities to corruption. The latter translates into (1) decreased costs, time, and complexity in inter-governmental and public-private information exchanges, (2) reduction of bureaucracy and discretionary power induced by Smart Contracts, and increased auditability of information in governmental registries and traceability of government transactions [34]. The final expected Impact is reducing corruption intent and prevalence, reinstating trust from citizens and companies into government processes through increased transparency and accountability, and ultimately fostering the pursuit of sustainable development in the region.

Assumptions of the model include overarching policy, decisions, and attitudes in the given context, next to technological advances (e.g. the emergence of challenger technology or technology maturity). Timeline \& scope refer 
to the preferred time-horizon and diffusion direction (bottom-up or top-down) of a given technology. A recapitulative overview of the integrative literature review can be found in Table 3. The items listed under each category correspond to the main findings of current academic literature on the topic.

\section{Comparable case studies}

To answer the first sub-research question, this section analyzes findings from the three case studies by conducting two semi-structured interviews and analyzing electronic documents. The case studies are analyzed and structured through the lens of the DOI theory, before being contrasted altogether to provide insights on the value proposition of BT and its uses in the Latin American public sector.

\subsection{Quintana Roo Congress, Mexico}

\subsubsection{Project description}

The Congress of the Quintana Roo state is the first local Congress in Mexico to have implemented blockchain technology for the digital certification of legislative documentation in the Correspondence and File Management System [36]. The objective of the project was to increase the transparency of the manipulation of information during legislative processes. Since its diffusion, whoever presents a new initiative obtains a QR code that, whenever scanned, will take the individual to the website where it can consult, download, and validate its document [36]. Using the Avalanche public blockchain, the legislative documents are transformed into non-fungible tokens (NFTs), while a hash is uploaded on the blockchain, which is how traceability is established. Avalanche is "an open-source platform for launching decentralized applications and enterprise blockchain deployments in one interoperable, highly scalable ecosystem" [17].

\subsubsection{Relative advantage}

The project allowed guaranteeing the integrity of legislative information in times of ensuring trust with citizens, entities, and deputies concerning the protection against the modification and destruction of initiatives presented [17]. Before implementing blockchain and digitalizing records, one could modify legislative proposal documents without leaving a trace, which represented a strong vulnerability to corruption. With blockchain, when delivering a digital archive of a legislative proposal, every modification has traceability in terms of time and person through the unique 'hash'. Solely the hash is published on the blockchain given documental weight. Modifying a single letter of a document would change the hash immediately, which is how the process is secured. The decentralized system prevents that only one person can edit documents, while the public and transparency aspect of the blockchainbased solution increases inclusivity [41]. Moreover, the decentralization through blockchain allows increased citizen engagement. Indeed, the capital city of the Quintana Roo state, Chetumal, used to be the only place to deposit an initiative for citizens, for which some were then required to travel long distances across the 10 state municipalities. As part of the project, each citizen may now do the process from a computer in their municipality.

\subsubsection{Compatibility}

Compatibility was relatively high in terms of alignment with the current digitalization strategy of the Mexican government. First, it is noteworthy to mention the role of the Covid-19 pandemic as a catalyzer of blockchain adoption. As using paper increased the risks of contamination, it was decided by the president of Congress, Gustavo Miranda Garcia, to digitalize records quickly, which led to the decision of using blockchain technology to limit the corruptibility of documents. Second, one of the most important elements that increased compatibility is the fact that approximately twenty years ago a system of electronic signatures was already implemented in México, creating a certain digital infrastructure that allowed a more seamless diffusion of blockchain [41]. Hence, implementing blockchain came from a long-term horizon in the transition to a Mexican national e-government. This is particularly important as past unsuccessful diffusions of blockchain were characterized by the fact that governments continued using paper next to blockchain infrastructure, defeating the purpose of the solution. In terms of compatibility with political will, the interviewee mentioned the importance of networking. Indeed, because of the pandemic, individuals from the technological sector employed in Mexico City moved to Cancún, located in Quintana Roo. The interactions 
and ideas generated by the migration and expansion of networking webs contributed to increasing political will [41].

\subsubsection{Complexity}

The diffusion of blockchain technology was initially found to be complex, as many traditional blockchain networks are congested and cannot scale to meet the needs of such solutions [17]. The project had initially started with Ethereum, however, the high transaction costs associated with the Ethereum public blockchain were prohibitive [41]. For this reason, after extensive market research and cost-benefit analysis, the government decided to go through with the Avalanche network from AVA Labs, which currently has more than 825 nodes distributed worldwide, and several alliances in Latin America, among which the LACChain of the Inter-American Development Bank (IDB) - a global alliance integrated by different actors in the blockchain sector and led by the IDB for the development of the blockchain ecosystem in Latin America and the Caribbean [17]. Transferring the solution developed in Solidity the programming language of Ethereum - was simple, as blockchain is characterized by high interoperability and scalability in this sense. The project required a multi-stakeholder and collaborative approach. AVA Labs provided the infrastructure, while the technology department of the Congress and another partner connected the Avalanche infrastructure with the one of the Congress. According to the interviewee, it was a relatively simple project, given the low number of legacy systems, allowing the project to start from the ground up [41].

\subsubsection{Observability}

As elections are approaching in Mexico, information on the observability of results could not be disclosed by the interviewee. Nevertheless, the current maturity of the market currently allows some proofs of concepts and pilot projects to present first satisfactory results [41]. By being a frontrunner initiative, using the technology is a symbol of willingness for transparency and modernization, which can then benefit from a phenomenon of mimicry in other governmental areas seeking to improve their information security processes [17].

\subsubsection{Trialability}

According to the interviewee, trialability involves two perspectives. From the technological point of view, it is optimal to go by phases, starting with a Proof-of-Concept (PoC), followed by a pilot project, and the official launch, hence adopting a bottom-up approach. In this regard, blockchain is adapted as an easily iterative technology, where modifications and optimizations throughout the process are possible. In terms of governmental strategy, as the governmental structure is centralized, a top-down approach is preferred. For example, an initiative is initially taken from the state capital, or a Congress, and goes down to the municipalities, and finally reaches the citizens. As previously mentioned, thorough cost-benefit analyses and research were needed before deciding to deploy blockchain. In this case, the government estimated that the costs of maintaining paper archival were greater than implementing it fully on the blockchain.

\subsection{Energía Abierta, Chile}

\subsubsection{Project description}

The National Energy Commission allegedly became the first public entity in Chile to use blockchain back in 2018 with the project 'Energía Abierta' [8]. The CNE wanted to make publicly available all micro- and macroinformation of the energetic components of the country, which are primordial for decision-making by the public sector, private sector, and wider population [19]. There was a need to secure the quality, accuracy, immutability, and transparency of that information to ensure trust among all stakeholders involved [8]. The project used the Ethereum public blockchain, where data is hashed and recorded on the blockchain so that the public has access to "real-time and unmodified energy information" on the CNE's website [8].

\subsubsection{Relative advantage}

Traditional databases are valuable in that they allowed for the digitalization of data; however, they were still prone to corruption as the centralized information was easy to hack or manipulate by third parties [5,19]. The CNE decided to use blockchain to improve the safety of energy data published on the platform since the decentralization and immutability of data recorded on blockchain makes it theoretically impossible to alter or delete information [5]. The public has now access to real-time and unmodified energy information that allows for simpler audits and 
more efficient, trustworthy markets [5]. When a public officer records data on the blockchain, the entire information chain towards higher levels of governance is immutable. According to the interviewee, the preventive power is the strongest as it signals that there is a control and that it is effective [19]. On the other side, the punitive power revolves around providing irrefutable proof during legal processes.

\subsubsection{Compatibility}

Independently of blockchain, there must be a governmental will to increase transparency in the projects [19]. According to the interviewee, the problem in Latin America is not necessarily the existence of corruption, but the inefficiency linked to its extensive bureaucratic processes, misunderstandings, and an overall lack of professionalism [19]. From a political strategy standpoint, the project worked because the government had a pre-existing platform of open government, next to structured data, which helped increase compatibility [19]. Hence, the launch of this project inscribed itself in a digitalization strategy, where the government was conscious of the benefits it may bring. The marketing of the project was done efficiently in the media, which also may contribute to a phenomenon of mimicry, as governments have a 'copycat' component that acts as a persuasive factor. In this sense implementing blockchain in places without corruption may increase the chances of diffusion in other, more corruption-prone sectors [19]. In terms of regulations, there was low compatibility legally. At this stage of development, the problem of blockchain revolves around the legal barriers of use at the governmental level since the payment of transactions on public blockchains needs to be done through cryptocurrencies, which the government itself does not legally recognize. Since governments do not recognize cryptocurrencies legally, they cannot dispose of blockchain transactions and need to hire third parties. Moreover, the lack of skilled programmers in Solidity means that even with political will, the government may lack resources to implement it due to the high cost of hiring programmers and their scarcity. These compatibility problems can be somewhat apprehended when accepting the input of the private sector, exemplified by the fact that the project was financed by the IDB.

\subsubsection{Complexity}

The complexity linked to the diffusion of blockchain in this context is related to the scalability challenge from Ethereum's high transaction costs paid through cryptocurrencies. More than not being compatible legally, Ethereum's costs threaten the financial viability of the solution. The presence of legacy systems also contributed to increased complexity in the diffusion.

\subsubsection{Observability}

In terms of observability, it is intricate to know whether there would have been an attempt to modify information had blockchain not been present, as "the best service is the one that cannot be seen" [19]. Indeed, the real benefits of blockchain can only be seen in the long-term, as reducing corruption does not revolve about the money that could be saved, but the capital that was not lost, hence the importance of the preventive and dissuasive message of using blockchain in a political sense. However, the interviewee mentioned that the relevance of using BT in the public sector blockchain technology can be studied comparatively. At the same time where the energy project with blockchain was successfully implemented, a case of corruption was observed in the Ministry of Economy, where officers changed on purpose the index of consumer prices. This occurrence was potent in highlighting the relevance of blockchain as its use was often criticized due to its cost and skepticism prevailed regarding its added value.

\subsubsection{Trialability}

The interviewee mentioned the need to start with small projects before moving on to a large diffusion of solutions, especially given the current costs of using public blockchains [19]. It is recommended to start implementing blockchain where there are not a lot of corruption instances and cultural difficulties, going from the simple to the complicated. Given the mimicry factor in governments, starting where there is no corruption might increase diffusion chances in corruption-prone sectors.

\subsection{The Transparency Project, Colombia}

\subsubsection{Project description}

The Transparency Project in Colombia is a multi-stakeholder initiative led by the WEF, in partnership with the IDB and the Office of the Inspector General of Colombia (Procuradoría General de Colombia), "to investigate, de- 
sign, and trial the use of blockchain technology for corruption-prone government processes" [12]. The project targeted the Programa de Alimentación Escolar (PAE) (i.e. public-school meal program), in charge of providing meals to vulnerable children across the country. The program is a historical site of procurement corruption in Colombia since a 2017 investigation revealed "disturbing irregularities in the pricing and delivery of food with contractors purchasing chicken breasts at four times the market price and 32 million meals going undelivered in 2016" [12]. In response to this issue, the project developed a blockchain-based software PoC in the format of an e-procurement public platform. Using the Ethereum public blockchain, the PoC was tested in a live procurement auction in Colombia in 2020, and primarily aimed to "(1) reduce instances of corruption in vendor selection in the public procurement process; and (2) serve as an efficacious mechanism for vendor selection” [12].

\subsubsection{Relative advantage}

The choice for a public blockchain was motivated by the possibility of data permanence and censorship resistance due to high system decentralization and security [12]. These features were considered highly relevant to fighting corruption, allowing the tender offer and modifications, the bidding process - including scoring and evaluation, and the public comments to be permanently recorded on the blockchain e-procurement system using cryptography and distributed consensus mechanisms [12]. Advantages, therefore, include real-time visibility of transactions, traceability, automated functions with Smart Contracts, and the reduction of centralized authority and information ownership within procurement processes [12].

\subsubsection{Compatibility}

Blockchain-based solutions are "unable to reduce corruption risk in certain human activities that can occur outside the electronic procurement system" [12]. Hence, digitalization strategies become once again relevant. In the case of the PAE, the case study recommended the revision of laws requiring in-person interactions or mandating paper bid submission, as they defeat the purpose of digitalizing processes with blockchain. Next to this revision, new policies compelling the use of e-procurement platforms may allow a complete shift to the e-procurement system, consolidating all transactions on a single database [12]. Only when there is an alignment between the initiative and the government's digital strategy can the solution be compatible with the institutional context. For this project, compatibility was notably increased by accepting the input of the private sector and transnational organizations, with the IDB and WEF. Hence, when the political will to increase transparency is not necessarily homogenous across a certain government, as exemplified by the fact that Colombia's own National Director of Anti-Corruption was accused of bribery and money laundering charges back in 2017, having the support of international organizations may foster compatibility [12].

\subsubsection{Complexity}

Several challenges increased the complexity of diffusion. The main challenge concerned solution scalability, both in the sense of node saturation and public blockchain costs. Indeed, Ethereum's network throughput was found to be prohibitive since data storage is expensive as data is "permanently stored and replicated on the thousands of nodes on the network" [12]. Another challenge concerned vendor anonymity, as vendors send transaction fees with their bid offers, which may reveal their identity as transactions are publicly viewable [13]. Finally, several security challenges could be foreseen, including the "crowding out of legitimate comments with fraudulent or low-value comments", and "permanent defamation of honest vendors in comments" [13]. Finally, the lack of interoperability between the official state public procurement system that needs to be compatible and integrated with the solution as mandated by law increased the technological complexity of diffusion. The challenges encountered may justify the need for hybrid blockchains, where "the Ethereum blockchain could be used to record hash records of bid and tender offers in a permanent and highly secure manner, while most other operations such as bid submission and evaluation decisioning could occur on permissioned" [13]. Nevertheless, innovations in the BT ecosystem may address certain challenges in the future.

\subsubsection{Observability}

In terms of observability, "the intentional secrecy of corruption poses a significant barrier to the assessment of anti-corruption programs" [12]. Nevertheless, several key performance indicators (KPIs) were developed to assess the success of the project, revolving around the blockchain-based e-procurement platform's performance in terms of transparency, accountability, prevention and fairness, and usability, effectiveness, and efficiency. In terms of 
observability and understandability of results, making information accessible and understandable by the public is primordial to be able to monitor activities, regardless of whether the public regularly logs on. Solutions should be comprehensive, with all resources on the same website to ensure full traceability of information and overview of processes. Finally, the project highlighted the need for intuitive and transparent solutions, intending to maximize participation by having a friendly user interface and user experience (UX) design while allowing the public to see the back end of the solution for trust purposes.

\subsubsection{Trialability}

This project was specifically launched to address the area's historic procurement corruption. As a software PoC, this project highlights the need for a technological bottom-up approach, which allows a close study of the contingencies needed to roll out blockchain-based solutions. Doing so also allows for audits and reviews from third-party security audits, and the full transition to the new system may then occur when the solution "successfully manages the procurement of complex purchases, services, and public works" [12]. The design phase should comprise of thorough cost-benefit analysis evaluating the value of implementing blockchain.

\subsection{Comparison of case study results}

The projects reviewed are still relatively rare in LATAM and present groundbreaking additions from which academia and politicians can learn. This section highlights the main similarities and differences between the case studies, adds insights from the expert survey to support results, and concludes on best practices.

\subsubsection{Relative advantage}

All projects made use of a public blockchain for the same reasons, namely permanent record-keeping, censorship resistance \& transparency, increased citizen engagement \& trust, information integrity, disintermediation, and decentralization; emphasizing that it would not be possible with another technology as of now and presenting an upgrade from traditional databases. These findings are corroborated by the structured questionnaire, where respondents indicated that immutability, auditability of records, and disintermediation were the characteristics of blockchain most relevant for fraud-proof systems. As such, blockchain has a real value proposition given both its preventive and punitive roles. Survey respondents overall considered blockchain as a future technology in the public sector of their respective countries, and as a potential solution to fight government corruption to a certain extent.

\subsubsection{Compatibility}

In terms of compatibility, all projects made clear that an alignment of the solutions with a governmental digitalization strategy is essential. As such, blockchain's compatibility is increased when its use inscribes itself in a long-term digitalization horizon. The decision to use blockchain represents both a prerequisite and an opportunity for the catalyzation of the digitalization of processes. Political will is primordial to implement blockchain, however, leveraging the phenomenon of mimicry in the public sector may be key to inspiring and convincing other sectors of the government to implement the technology as it gains in maturity and legitimacy. The lack of political will and understanding of BT from government officials may also be countered by accepting the input of transnational organizations and fostering national networking, education, and innovation. As such, the three projects had a link with the IDB and the LACChain, showing the relevance of the financial and private sector in the adoption of the technology. Overall, what becomes important is the need for Latin American governments to remove legal barriers when using blockchain in terms of its legal status (e.g. cryptocurrencies for transaction fee payment), but also by mandating the transition to fully online systems.

\subsubsection{Complexity}

In the case of México and Chile, pre-existing digital infrastructure contributed to a simpler diffusion, the former also having benefitted from low levels of legacy systems. Meanwhile, the Colombian case encountered challenges as low digital infrastructure was present, and the solution needed to be compatible by law with current legacy systems. The same challenges, however, were mentioned in each project, namely the scalability challenge due to node saturation and the transaction costs of public blockchains. Given technological and legal limitations, hybrid forms of blockchain may be more adapted by gathering advantages from both permissioned and public blockchains, reducing the cost of transactions, and requiring less computing power. Hybrid blockchains were also indicated to be 
most adapted overall by experts in the survey. Another solution as seen in the Mexican case is to use alternative and cheaper public blockchain network providers besides Ethereum. Moreover, this complexity may be apprehended in the future as the technology gains in maturity and limitations are lifted.

\subsubsection{Observability}

Observability is ensured by the fact that blockchain is used to make information accessible and understandable usually by publicly displaying real-time data on the governmental bodies' websites. Data displayed should be intuitive to understand for the wider public. In terms of the observability of intended outcomes concerning avoided corruption intent, the Mexican and Chilean cases emphasize that it is not possible to quantitatively assess the benefits of blockchain as assessing what has not been lost to corruption is impossible. Nevertheless, it can be inferred if there are occurrences of corruption in sectors without BT. The case from Colombia puts forward a set of KPIs as a proxy of success, which represents a promising line of inquiry to make blockchain use cases more compelling.

\subsubsection{Trialability}

All cases highlight the possibility of having pilot projects before officially launching blockchain projects. While the decision to use blockchain needs to be top-down, the diffusion should follow a bottom-up, multilateral approach as the technology gradually increases in maturity and becomes regulated. Extensive cost-benefit analyses are necessary to justify the upgrade from traditional databases. México and Chile are successful examples of diffusion and do not show severe shortcomings as of now. The Colombian case remains to show effective results. This is due to the choice of area consideration. While the former projects were implemented in areas with relatively low historical corruption, which may benefit from mimicry to more corruption-prone sectors, the Colombian case was purposely implanted in a highly corrupted area, which justifies the higher level of skepticism and diffusion challenges encountered.

\section{Integration of survey results with literature review}

While the case studies served to prove the relevance of using blockchain for LATAM governments, this section tests the diffusion model (Fig. 1) by compiling results from the structured questionnaire and the literature review into the Smart Governance BT diffusion model (Fig. 3). The different elements in the final Smart Governance BT diffusion model are based on the lists of items from the literature review as seen in Table 3 and are ranked based on the mean and standard deviation of survey responses, as participants were asked to rank the salience of items considering their country. Ultimately, before deploying blockchain, governments must be "clear about the problems they want to address, the feasibility of blockchain-based solutions, and the value these can add" [32]. Overall, the Problem statement of the model is that the current inefficiencies in the Latin American public sector as outlined in Table 2 generate vulnerabilities to corruption.

Next, considering the indicators for the political, technological, and socio-economic readiness dimensions of the Inputs section, a ranking of readiness of 14 countries in the Latin American region is provided based on available data from quantitative indicators (Fig. 2). Countries at the top of the ranking are in the best position to benefit from blockchain's attributes, while countries on the lower end may need to develop other requirements prior, with a focus on the digitalization of the public sector. It is noteworthy to mention that the three countries where case studies were analyzed - Chile, Mexico, and Colombia- are in the top 5 of the readiest countries to implement blockchain. Chile is characterized by a high political readiness, as seen by the solution being implemented at the ministry level. The relatively high technological readiness of Mexico is corroborated by findings from the case study on the country's pre-existing digital signature system. Finally, the low socio-economic readiness of Colombia was exemplified by the need for global experts to implement the technology within the PAE.

Once prerequisites are fulfilled, and a Latin American government decides to use blockchain in a certain field, the diffusion enters a Dynamic throughput, where the diffusion Challenges and Considerations \& risks associated with BT must be apprehended by the proper Policy implications and Activities. The entire Dynamic throughput must be seen as a parallel and iterative process.

In terms of diffusion Challenges, security concerns, integration with legacy systems, and scalability of solutions were indicated as the main obstacles along the road to technology diffusion. The fact that blockchain needs to be 


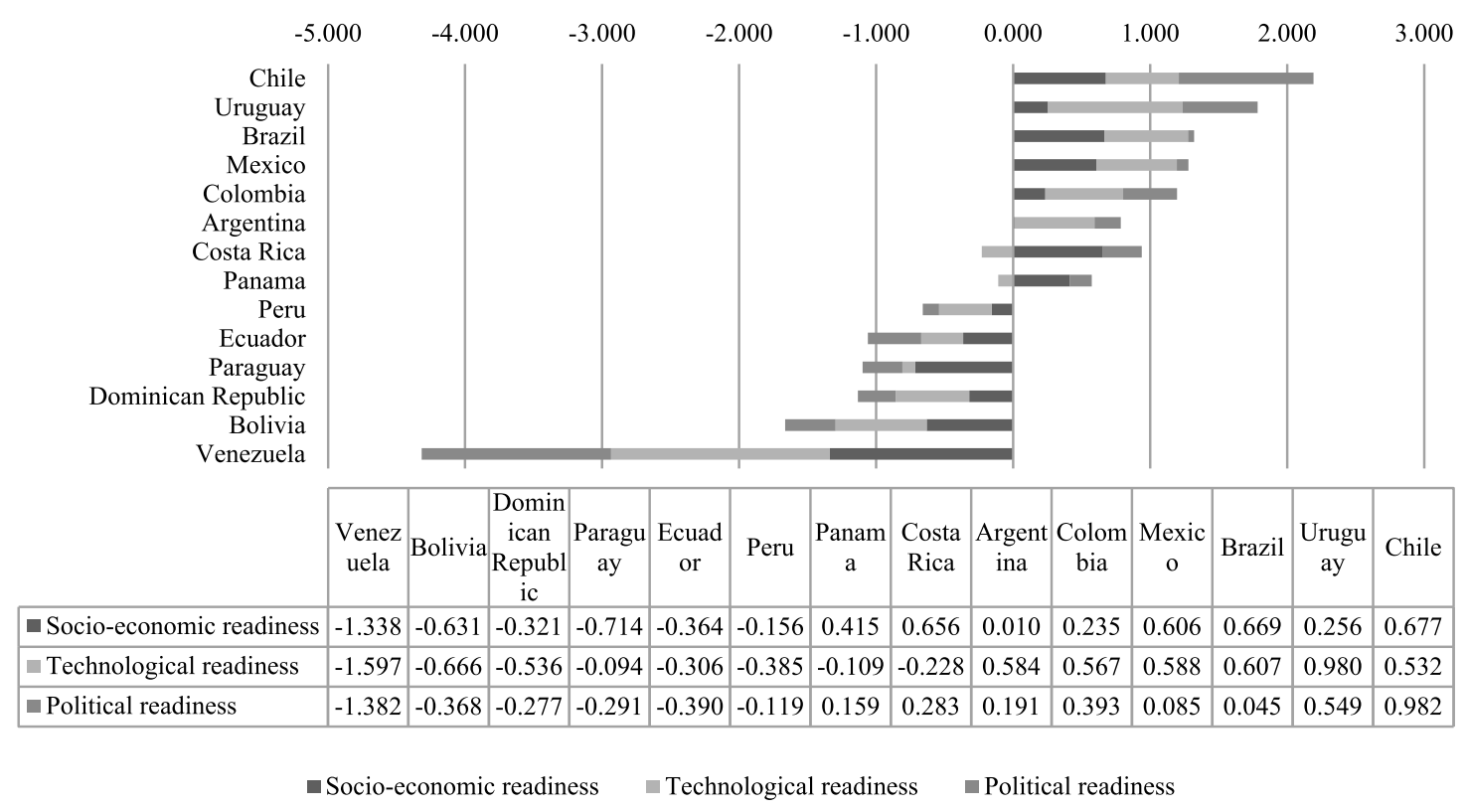

Fig. 2. Decomposition of blockchain readiness of adoption index by pillar.

combined with other technologies to develop its potential as an anti-corruption tool, the need for trusted gatekeepers, and the excessive speculation over its actual potential were said to be the main Considerations \& risks involved in its diffusion. Hence, the most salient Policy implications were creating a supportive ecosystem nurturing start-ups and promoting PPPs next to developing human capital and building a regulatory model around the technology.

Therefore, Activities for Latin America include gradually setting up a scene of blockchain diffusion within the Latin American public sector, which mainly involves redesigning and streamlining processes, conducting thorough cost-benefit assessments to determine which areas require a database change, prioritizing hybrid blockchains, and building cross-sector partnerships. This is especially relevant as bad processes implemented in blockchain remain flawed. As such, there needs to be more education and understanding of BT, both for elected and commissioned officials and the general public, while qualified tech workers should be incited to enter the government. Indeed, the tradeoffs in terms of governance centralization, transparency, and costs associated with the use of private, public, and hybrid blockchain need to be considered before deciding on which configuration is most appropriate to a certain use case. Finally, international cooperation is needed to support GovTech initiatives that can add to the effort from the local governments.

Blockchain's main features revolve around immutability, trust, coordination, security, and transparency. In terms of Outputs, asset registry was indicated to be the most important application of BT, followed by tracking transactions, verifying identity, and e-voting. Falling into these broader categories, respondents indicated specific use cases, such as (1) Citizen Digital Identity, (2) easy request for official documents and government services from digital wallet (3) efficient issuing of fraud-proof digital documents, (4) portable, verifiable digital documents with QR scanning and digital wallet sharing option, (5) interchangeable NFTs to represent ownership, (6) tokenizing participation and taxes towards country digital currency, (7) local, state and national interoperability, and (8) international interoperability. The role of the private sector and IDB's LACChain were mentioned, as well as the need for seamless blockchain integration that allows politicians to use the technology more intuitively, the key message being that seamless integrations may allow for higher adoption rates, similar to how apps are used without requiring users to understand the functioning of the back end. Non-blockchain-based databases employing cryptography, such as Public Key Infrastructure (PKI) were also mentioned as an alternative to blockchain given its limitations, as they "also create record-keeping systems where documents or record modifications would be difficult and evident" [13]. Nevertheless, these systems do not prevent a central administrator from deleting records entirely, unlike blockchain. 
As previously mentioned, Outcomes are expected to be a reduction in the vulnerabilities to corruption, a reduction in costs, time, and complexity in inter-governmental and public-private information exchanges, less bureaucracy and discretionary power, increased auditability of information, and traceability of government transactions. The intended final Impact is reducing corruption intent and prevalence, reinstating trust through increased transparency and accountability, and ultimately enabling sustainable development. Monitoring progress through KPIs can help governments target continuous improvements. These KPIs should include both process and outcomes measures, to be fed back into the dynamic throughput as insights are generated from each measurement period [42].

In terms of Timeline \& scope, as seen throughout the case studies and survey, approximately 10 years would be necessary for their country to adopt blockchain technology on a wider scale within Latin American governments, going from pilot projects to functioning programs, and as legacy institutions are fixed and the technology gains in maturity. In the meantime, country benchmarks (e.g. Estonia) and private sector initiatives are key learning hubs for national governments. The use of blockchain depends on its effectiveness and efficiency in diffusion and not merely on its adoption, highlighting a need for continuous monitoring that it is being used adequately. Finally, rules and regulations need to change and become easier for people and businesses to follow to be valid for implementation in a blockchain-based system. The scope of diffusion implies a bottom-up approach technologically and a top-down approach politically, aiming to leverage mimicry phenomenon in the public sector by targeting less corrupted sectors first.

Assumptions of the model include (1) the gradual maturity of blockchain technology, (2) its acceptance and surrounding regulations given its particularities and environmental impact, next to the overall behavior, attitudes of governments towards the fight against vulnerabilities to corruption, and (3) the stability of the region. Assumptions shall not ignore the potential rise of competing or more adapted technologies. Moreover, not all types of corruption mechanisms can be apprehended by merely a switch of technology. Several factors such as physical monetary transactions remain untraceable, although they may be apprehended by the digitalization of the public sector, showing the interconnectedness of the framework. Indeed, using blockchain for registering assets such as land registries does not solve the issue of formalizing property ownership or ineffective governance, and cannot work on non-existent, incomplete, or incorrect databases [13]. In terms of tracking transactions, individuals and organizations that are less technologically savvy and unable to use the system may face exclusion. Moreover, blockchain-based transaction tracking systems do not address how the capital itself is later disbursed. Hence the avoidance of corruption should not be taken for granted [13]. Finally, the high stakes in using blockchain for voting systems remains questionable given the technology's security risks and low maturity. The final pathway of diffusion for blockchain technology within the Latin American Context is presented in Fig. 3, aiming to provide insight to researchers and policy-makers alike on the considerations related to blockchain adoption in the Latin American public sector.

Although some degree of stability is required, facing governance challenges tends to lead countries to be early blockchain adopters [29]. This aspect makes studying the Latin American region insightful and relevant for other contexts. The model may be tested for any Smart Governance initiative requiring conceptualization, whether in terms of the technology type (e.g. IoT, Energy Data Management System) and scope concerned. Finally, city-level or initiative-based analyses rather than regional overviews may provide increased insights to governments.

\section{Discussions}

Moving away from viewing blockchain merely through its application in cryptocurrencies, the value proposition of the technology for reducing vulnerabilities to government corruption in Latin America at this stage of development is ambiguous. At the bottom line, "technology cannot fully solve what is at the heart of human behavior problems" [12]. Nevertheless, while it is an overstatement that blockchain will solve corruption and there must be certain management of expectations, it most certainly can contribute to the reduction of current vulnerabilities to corruption in Latin America for two main reasons, namely (1) reducing inefficiencies in the public sector, and (2) acting as a dissuasive and evidence mechanism for fraud. Indeed, the "expectation of being observed and examined serves as a compelling deterrent for individuals who may otherwise consider engaging in corruption" [40]. 


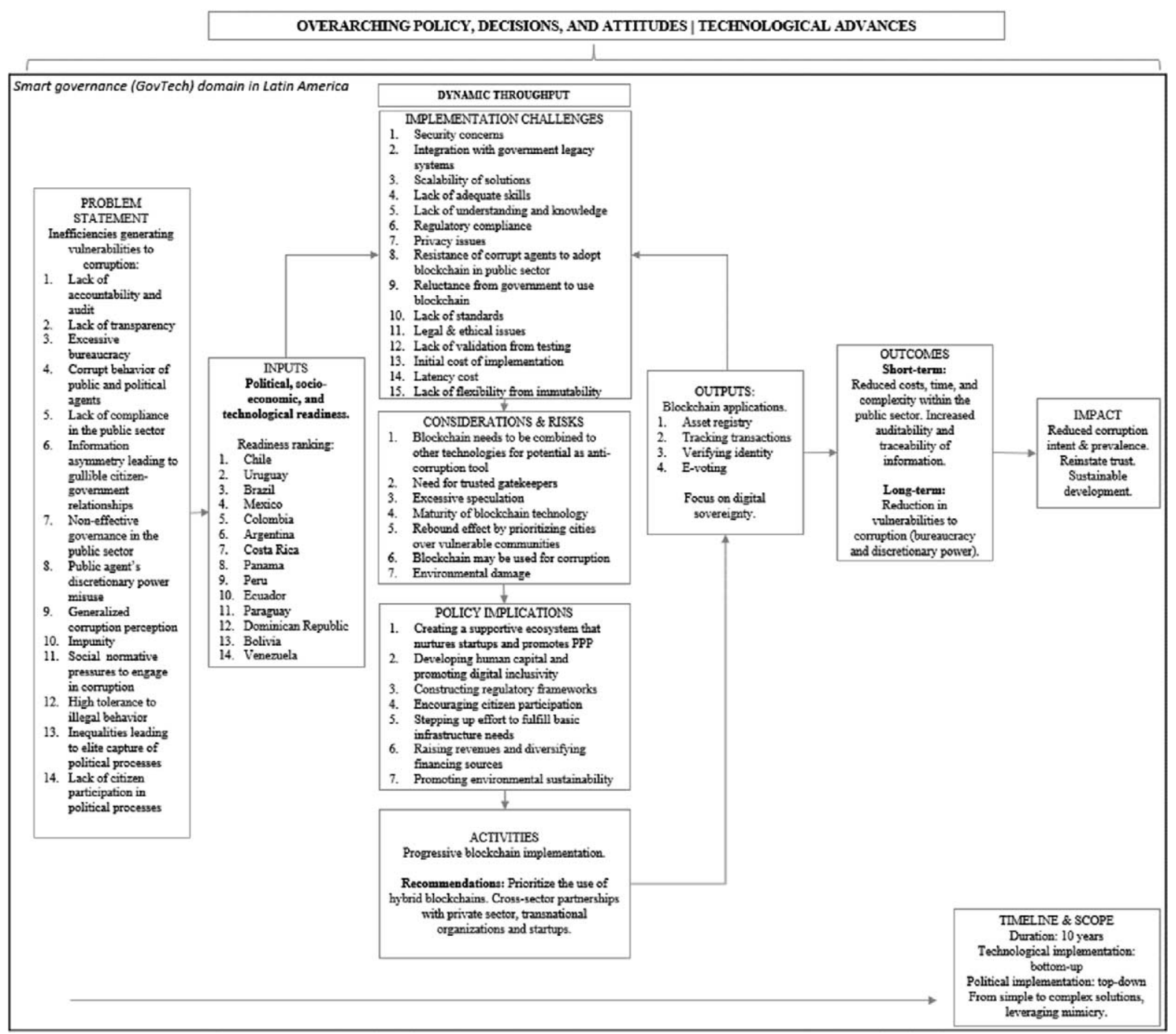

Fig. 3. Smart Governance BT diffusion model for Latin America.

The difficulty in establishing the real value proposition of blockchain for the public sector lies in the fact that the cost-benefits of blockchain for corruption are not readily seen, both in terms of the impossibility of assessing the corruption avoided and given current technological and institutional limitations.

The present study results showed that it is important not to leapfrog stages of development by implementing blockchain, as flawed processes within the blockchain have no added value. This led to the identification of the socio-economic, political, and technological pillars of readiness associated with the diffusion of blockchain technology. Ultimately, implementing blockchain in corruption-prone sectors relies upon pre-existing digitalization strategies and political will to increase transparency. Furthermore, despite their blockchain adoption readiness, the wider diffusion of BT will only be possible when countries digitalize their records and recognize the technology in their regulations. Regulations must evolve in terms of enforcing digitalization and regulating the legitimate use of blockchain. In terms of socio-economic relevance, the role of the private sector and start-ups should not be downplayed. Cross-sector partnerships and developing an ecosystem that fosters and supports innovation are essential to be able to seamlessly build the future technological scene and tech-savviness of the country. In terms of technological relevance, this paper highlighted the importance of node saturation and scalability challenges from high costs, 
next to the technology's environmental impact. Nevertheless, the latter may be mitigated by the transition to greener fuels or alternative forms of consensus mechanisms.

For a technology to be truly disruptive, it needs to be implemented on a wide scale. Given the limitations and challenges of BT at this stage of development, a thorough cost-benefit analysis is required first to ensure the technology presents enough benefits to motivate a database change for specific use cases. A key takeaway involves the difficulty of implementing blockchain-based pilot projects in places with historically high levels of government corruption. This occurrence suggests that projects should rather be implemented in areas less prone to corruption in the first instance, which may later induce a phenomenon of mimicry in the public sector towards corruption-prone areas as the technology gains maturity and legitimacy. While a bottom-up strategy from a technological standpoint is prioritized, a top-down, centralized approach is needed in terms of political will and decision-making.

Even if blockchain is ultimately not implemented, the final model constitutes a model for positive development for the region and highlights the need to transition to smarter governments leveraging the GovTech entrepreneurial space. The debates surrounding blockchain and its characteristics present an important line of inquiry for the future of the notion of inclusivity in LATAM. The next decade will be decisive in its true potential for the region and will require monitoring, research, collaboration, and education. Private sector initiatives such as the LACChain represent a promising line of change, while crises such as the Covid-19 contribute to the catalyzation of the digitalization of the region.

\section{Conclusion and future research}

As one of the first attempts to research this subject in such depth, this paper does not aim to prescribe using blockchain, but rather to conceptualize, make sense of, and demystify the diffusion of blockchain in the Latin American public sector. Despite all the literature reviewed, previous research rarely comprehensively addressed the topic, nor was it able to perform reliable and thorough qualitative and quantitative research, which prevented proving causality of any sort and prompted the use of non-academic resources. These limitations further justified the creation of two conceptual models - a Blockchain Readiness Composite Indicator (BRCI) and the Smart Governance BT diffusion model - for the adoption and diffusion of blockchain technology in the Latin American public sector that are deemed more valid than previous research.

There is a need to nuance the link between blockchain and corruption, which is often bridged in papers and the media. BT is a tool to help reduce inefficiencies that give place to vulnerabilities to corruption but does not represent a solution to corruption per se. Moreover, rather than considering blockchain as a self-contained phenomenon, its diffusion within governments must inscribe itself as part of a wider digitalization and reform strategy. Hence, for now, the power of blockchain does not entirely lie in the technology, but rather in how "it has reframed many discussions across various parts of our society and economy" and contributes to catalyzing change within Latin American governments as they start considering the technology and realize the necessary conditions lacking [20].

This paper presents several limitations calling for future research to replicate findings and investigate new lines of inquiry. Blockchain is seen as a revolutionary technology in terms of its characteristics to reduce inefficiencies, but is not a panacea, as there is still a risk that it is used for corruption purposes, and its low maturity may bring security issues. Hence, resources may be better spent on fixing current inefficiencies rather than on implementing the technology straight away. The high energy consumption in its mining also consists of a considerable pitfall that highlights that blockchain should only be implemented when a clear benefit can be achieved compared to its environmental and financial costs.

Current definitions of blockchain are heterogeneous. The lack of consensus on the technology's definition and typology, especially exemplified by sometimes contradictory definitions in academic papers and non-academic sources hinder appropriately framing the value proposition of the technology. Most of the technology's terminology is also lacking from dictionaries, preventing standardized definitions to be used. Several sources mention 'private blockchains' as another word for permissioned blockchains, however survey respondents indicated the term is inappropriate and fictitious.

Certain results may not be free from bias as survey and interview respondents are in majority blockchain experts involved in current projects and their geographical dispersion is not weighted. Nevertheless, certain skepticism 
levels from respondents could be noticed, indicating that results do not necessarily suffer from a positivistic bias. This study may lack certain leverage in terms of expert answers gathered due to a lack of financial and capacity means. Hence results are meant to be anecdotal and should not be treated as representative of the Latin American sentiment. The listing of contingencies shall also not be treated as exhaustive, although the author attempted to represent all main contents of current research on the topic.

As results only concern a selection of 14 Latin American countries out of 33 based on data availability, this paper may have an overgeneralization of the Latin American region. It is also advised to conduct a city-level readiness analysis for blockchain. Current data do not allow to do it as of now, but qualitative research and increased use cases analysis could provide more insights in this area. There is a significant disconnect between what is happening in Latin America and what is reported in international academia. Much more use cases are available than those mentioned in current research or databases. Overall, this paper aimed to touch upon all aspects of blockchain in Smart Governance initiatives in LATAM, opening the branch for further refined research on each topic mentioned.

\section{Acknowledgements}

The authors thank Ricardo Vázquez Gutiérrez and Marcos Ariel Malamud for their time in the interviews and all the 30 blockchain and GovTech experts who contributed to the research project and provided constructive feedback. The authors would also like to express their gratitude to the four anonymous reviewers for their valuable comments.

\section{Conflict of interest}

None to report.

\section{Appendix A. Sample and respondent statistics}

Crunchbase start-up initial sample statistics (total of 246 start-ups): Argentina (22), Bolivia (1), Brazil (128), Chile (14), Colombia (14), Costa Rica (8), Dominican Republic (2), Ecuador (1), Mexico (34), Panama (8), Paraguay (2), Peru (4), Uruguay (5), Venezuela (3).

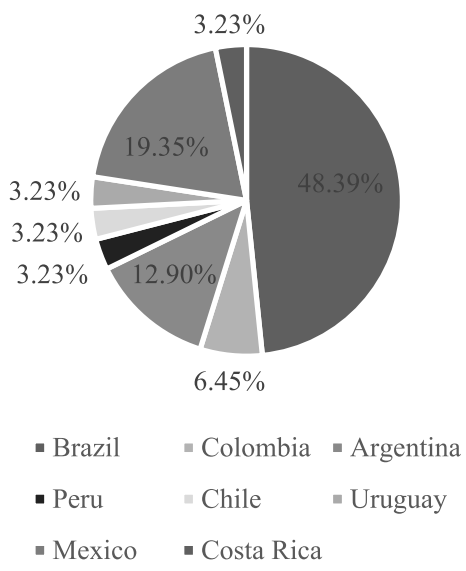

Fig. 4. Distribution of country respondents $(N=30)$. 


\section{Appendix B. Research structure}

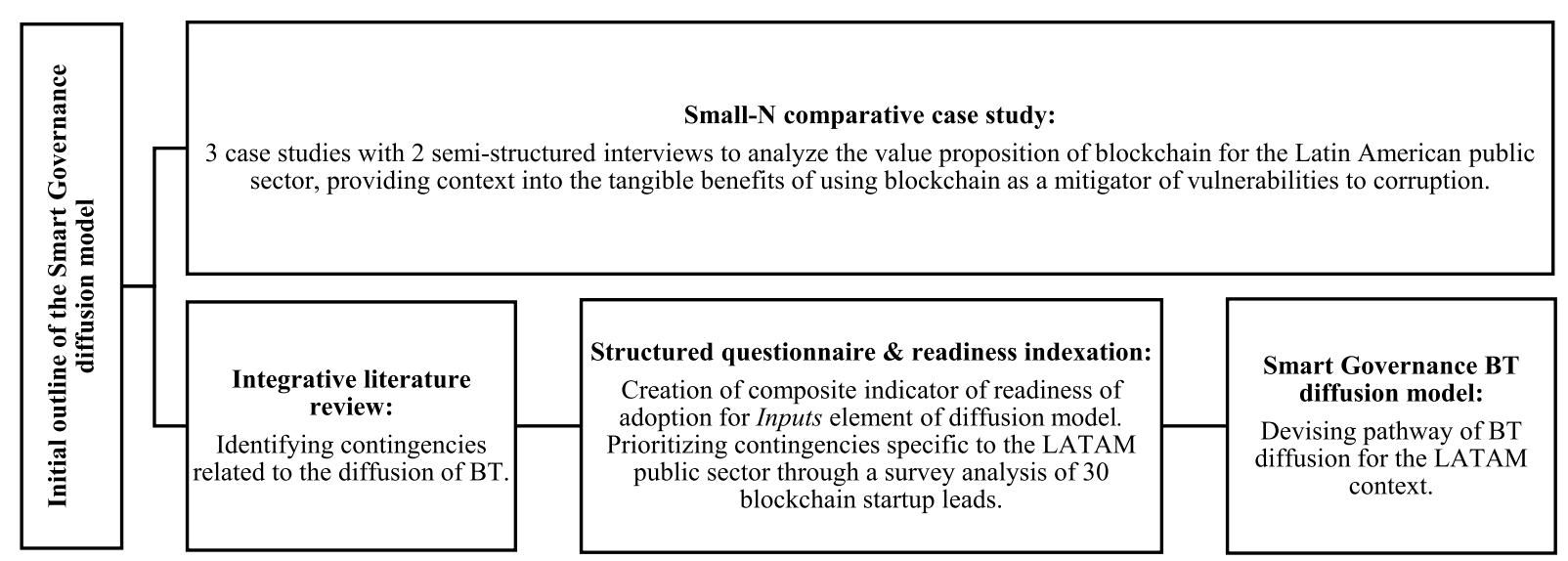

Fig. 5. Research structure.

\section{References}

[1] P. Aarvik, Blockchain as an anti-corruption tool, U4 Issue (2020).

[2] Z. Aliyev and I. Safarov, Logos, mythos, and ethos of blockchain: An integrated framework for anti-corruption, in: OECD Global AntiCorruption \& Integrity Forum, Paris, 2019.

[3] A. Anderson, The Community Builder's Approach to Theory of Change, The Aspen Institute, New York, 2006.

[4] S. Balasubramanian, V. Shukla, J.S. Sethi, N. Islam and R. Saloum, A readiness assessment framework for blockchain adoption: A healthcare case study, Technological Forecasting \& Social Change 1(16) (2021).

[5] M. Barley, Chile uses blockchain to increase trust in energy market data, 2018, available from Ledger Insights: https://www.ledgerinsights. com/chile-blockchain-energy-data/.

[6] R. Campos, World Bank rejects El Salvador request for help on bitcoin implementation, 2021, available from Reuters: https://www.reuters. com/business/el-salvador-keep-dollar-legal-tender-seeks-world-bank-help-with-bitcoin-2021-06-16/.

[7] A. Chomcyzk, Regulación de blockchain e identidad digital en América Latina: el futuro de la identidad digital, IDB, 2020.

[8] C.N.E. Comisión, Nacional de Energía se convertirá en la primera entidad pública en utilizar Blockchain en Chile, 2018, available from Comisión Nacional de Energía (CNE): https://www.cne.cl/prensa/prensa-2018/febrero-2018/comision-nacional-de-energia-se-convertiraen-la-primera-entidad-publica-en-utilizar-blockchain-en-chile/.

[9] Crypto Climate Accord, Make crypto green, 2021, available from Crypto Climate Accord: https://cryptoclimate.org/.

[10] M. Higginson, M.C. Nadeau and K. Rajgopal, Blockchain's Occam problem, 2019, available from McKinsey \& Company: https://www. mckinsey.com/industries/financial-services/our-insights/blockchains-occam-problem.

[11] IDB, Exploring Blockchain Technologyfor Government Transparency: Blockchain-Based Public Procurement to Reduce Corruption, World Economic Forum, Geneva, 2020.

[12] IDB, Insight Report: Exploring Blockchain Technology for Government Transparency: Blockchain-Based Public Procurement to Reduce Corruption, World Economic Forum, 2020.

[13] IDB, Supplementary Research Report: Exploring Blockchain Technology for Government Transparency: Blockchain-Based Public Procurement to Reduce Corruption, World Economic Forum, 2020.

[14] E. Iosif, K. Christdodoulou and A. Vlachos, A robust blockchain readiness index model, 2021, arXiv preprint arXiv:2101.09162.

[15] P. James, R. Astoria, T. Castor, C. Hudspeth, D. Olstinkske and J. Ward, Smart Cities: Fundamental concepts, in: Handbook of Smart Cities, J.C. Augusto, ed., Springer International Publishing, London, 2019, pp. 3-34.

[16] N. Kshetri, Will blockchain emerge as a tool to break the poverty chain in the Global South?, Third World Quarterly (2017), 1710-1732.

[17] A.V.A. Labs, Congreso de Quintana Roo en México usa Blockchain de Avalanche para Optimizar Transparencia en su Proceso Legislativo, available from AVA Labs: https://medium.com/avalanche-es/congreso-de-quintana-roo-en-m\%C3\%A9xico-usa-blockchain-de-avalanchepara-optimizar-transparencia-en-su-ec95036eecbe; n.d.

[18] E. Luciano, O. Magnagnagno, R. Souza and G. Wiedenhoft, Blockchain potential contribution to reducing corruption vulnerabilities in the Brazilian context, in: 2020 Seventh International Conference on eDemocracy \& eGovernment (ICEDEG), IEEE, 2020, pp. 135-142.

[19] M.A. Malamud, Case study: Energia Abierta in Chile, C. Parenti, Interviewer, 2021. 
[20] C. Mulligan, Blockchain and sustainable growth, available from United Nations: https://www-un-org.eur.idm.oclc.org/en/un-chronicle/ blockchain-and-sustainable-growth; n.d. doi:10.18356/c78b1d78-en.

[21] E. Nagel and J. Kranz, Smart city applications on the blockchain: Development of a multi-layer taxonomy, in: Blockchain and Distributed Ledger Technology Use Cases: Applications and Lessons Learned, H. Treiblmaier and T. Clohessy, eds, Springer, 2020 , pp. $201-226$. doi:10.1007/978-3-030-44337-5_10.

[22] Netherlands Enterprise Agency, Developing your theory of change, 2018, available from Netherlands Enterprise Agency: https://english. rvo.nl/sites/default/files/2018/11/FBK_theory_of_change_guidelines_0.pdf.

[23] N. Noori, T. Hoppe and M.d. Jong, Classifying pathways for smart city development: Comparing design, governance and implementation in Amsterdam, Barcelona, Dubai, and Abu Dhabi, Sustainability (2020), 4030.

[24] N. Noori, M.d. Jong and T. Hoppe, Towards an integrated framework to measure smart city readiness: The case of Iranian cities, Smart Cities (2020), 676-704. doi:10.3390/smartcities3030035.

[25] N. Noori, M.d. Jong, M. Janssen, D. Schraven and T. Hoppe, Input-output modeling for smart city development, Journal of Urban Technology (2020), 71-92.

[26] OECD, Handbook on Constructing Composite Indicators, OECD, 2008.

[27] G. Pereira, E. Estevez, D. Carona, C. Chesñevar, P. Cllazzo-Yelpo, M.A. Cunha, et al., E.M. Luciano, South American expert roundtable: Increasing adaptive governance capacity for coping with unintended side effects of digital transformation, Sustainability (2020), 0-47.

[28] N.P. Rana, Y.K. Dwivedi and D.L. Hughes, Analysis of challenges for blockchain adoption within the Indian public sector: An interpretive structural modelling approach, Information Technology \& People (2021).

[29] C. Reddick, G.P. Cid and S. Ganapati, Determinants of blockchain adoption in the public sector: An empirical examination, Information Polity (2019), 379-396.

[30] N. Renteria, T. Wilson and K. Strohecker, In a world first, El Salvador makes bitcoin legal tender, 2021, available from Reuters: https:// www.reuters.com/world/americas/el-salvador-approves-first-law-bitcoin-legal-tender-2021-06-09/.

[31] R. Rotberg, The Corruption of Latin America, Springer, 2019.

[32] C. Santiso, Will blockchain disrupt government corruption?, 2018, available from Stanford Social Innovation Review: https://ssir.org/ articles/entry/will_blockchain_disrupt_government_corruption\#.

[33] C. Santiso, Here's how technology is changing the corruption game, 2019, available from World Economic Forum: https://www.weforum. org/agenda/2019/02/here-s-how-technology-is-changing-the-corruption-game/.

[34] C. Santiso, Hacking corruption in the digital era: How tech is shaping the future of integrity in times of crisis, World Economic Forum, 2020.

[35] S. Sayeed and H. Marco-Gisbert, Assessing blockchain consensus and security mechanisms against the 51\% attack, Applied Sciences 9(9) (2019), 1788. doi:10.3390/app9091788.

[36] C. Social, Congreso de Quintana Roo, primero en utilizar tecnología blockchain, 2020, available from Comunicación Social: http:// comunicacion.congresoqroo.gob.mx/20210301/congreso-de-quintana-roo-primero-en-utilizar-tecnologia-blockchain/.

[37] S.Y. Tan and A. Taeihagh, Smart city governance in developing countries: A systematic literature review, Sustainability (2020), 899.

[38] E. Toufaily, T. Zalan and S.B. Dhaou, A framework of blockchain technology adoption: An investigation of challenges and expected value, Information \& Management (2021), 1-17.

[39] H. Treiblmaier and C. Sillaber, A case study of blockchain-induced digital transformation in the public sector, in: Blockchain and Distributed Ledger Technology Use Cases: Applications and Lessons Learned, H. Treiblmaier and T. Clohessy, eds, Springer, 2020. doi:10. 1007/978-3-030-44337-5.

[40] M. Trivunovic, J. Johnson and H. Mathisen, Developing an NGO corruption risk management system: Considerations for donors, U4 Issue (2011).

[41] R. Vázquez, Case study: Blockchain in Quintana Roo Congress, C. Parenti, Interviewer, 2021.

[42] K. Vu and K. Hartley, Promoting smart cities in developing countries: Policy insights from Vietnam, Telecommunications Policy (2018), $845-859$.

[43] E. Zapata, R. Stirling, W. Pasquarelli and E. Shearer, The GovTech Index 2020 unlocking the potential of GovTech ecosystems in Latin America, Spain, and Portugal, CAF, 2020.

[44] N. Zúñiga, Correlation between corruption and inequality, U4 Anti-Corruption Centre, 2017. 